Res Pública Revista de Historia de las Ideas Políticas

ISSN: 1131-558X

http://dx.doi.org/10.5209/rpub.70465

\title{
F. Duque Pajuelo, Filosofía de la Técnica de la Naturaleza, Madrid, Abada, 2019, $539 \mathrm{pp}$.
}

Con el título Filosofía de la Técnica de la Naturaleza, presenta Félix Duque una importante síntesis de una de las ramas de investigación a las que se ha dedicado a lo largo de su carrera. En palabras del mismo autor, esta obra de 2019 viene a culminar -al menos por el momento- un libro cuyos orígenes se remontan ya a los años ochenta del pasado siglo. Descatalogado desde hace tiempo, aunque reeditado más recientemente (2014) en Colombia, el texto embrión de la presente obra se quedaba a las puertas de vislumbrar las transformaciones socio-tecnológicas advenidas en las últimas décadas del siglo XX y principios del XXI. En ese sentido, con la edición de 2019, Duque se propone a la vez remachar una "antigua tarea pendiente" pero sobre todo dialogar desde ella con las circunstancias que marcan la tesitura presente.

Entrando en harina filosófica, el catedrático de la Universidad Autónoma de Madrid desarrolla en este libro una auténtica filosofía de la historia en clave tecnológica. Partiendo de una clara visión heideggeriana de la historia como desplegarse del ser a través del concomitante desvelamiento del mismo a través de la técnica, Félix Duque se esfuerza por dejar claro desde el principio una idea: historia natural e historia social no se encuentran separadas por ninguna suerte de "salto" o "novum onthologicum", sino que más bien la historia humana y la natural van íntimamente de la mano, de tal forma que el hombre hace su historia "en", "con" y "por" la naturaleza. El pliegue sobre sí mismo del entorno da lugar al organismo humano, origen de la historia social; y de ello se sigue que la autoconstitución del hombre en la naturaleza no es más que un proceso de constitución de la naturaleza en el hombre.

La técnica aparece, pues, como matriz de todo este proceso. El trabajo y el empleo de útiles de todo tipo por parte del hombre en la faena de su "hacerse" abre nuevas posibilidades de ser a la naturaleza. Ahora bien, estas posibilidades no son arbitrarias o aleatorias sino que responden a un entramado (Gefühge) que, al hilo de la acción del hombre, iría cristalizándose progresivamente. La demarcación entre Naturaleza y Cultura radicaría, según esto, única y exclusivamente en una diferencia de perspectivas dentro de un mismo plexo de referencias. Por consiguiente, el proceso cultural atendría a la reproducción de saberes y reglas prácticas normalizadas -las cuales asegurarían el éxito y la pervivencia de la especie gracias a su correcta adaptación al medio-; mientras que el cultural lo haría a la invención de esos saberes -o sea, a la redistribución del flujo energético dentro de la comunidad-.

A partir de aquí, el profesor Duque ofrece una visión de la historia tecno-natural -o material- del hombre basada en la sucesión de diferentes estadios. El desequilibrio entre casta dirigente -controladora del proceso de transmisión de saberes- $\mathrm{y}$ grupos portadores de invención -responsables del surgimiento de nuevas técnicasgeneraría un dinamismo histórico basado en el establecimiento de sucesivos órdenes sociales en función de los avances técnicos y de las posibilidades de vida ofertadas por estos. Revolución social y revolución tecnológica irían de la mano para el profesor... ahora bien, no de una forma causal directa, sino más bien en una continua interrelación mutua. Con todo esto, puede hablarse -según Félix Duque- de un sentido natural del desarrollo histórico: la producción de riquezas (trabajo) y su distribución generadora de poder (economía+política) dependen de la creación de recursos y éstos, a su vez, de realizaciones técnicas. La historia de la humanidad se correspondería con la progresiva captación por parte del hombre del "saber hacer" presente en la naturaleza y en su consiguiente reproductibilidad y mayor adaptación a la misma. En este sentido, y aquí radica una importantísima observación de Félix Duque, el proceso de invención es previo tanto al grupo social como al entorno físico mismo. Ahora bien, este no existe antes sino que se da en esos factores en la forma en que se agota en el mero dar sentido a los términos de la relación. La invención (in-venire; sym-ballein) es previa, más no como entidad sino como principio de inteligibilidad y génesis. Yéndonos a la etimología germánica de cosa (thing: asamblea), podemos decir -junto con el catedrático de la UAM- que no hay propiamente cosas sino relaciones técnicas que segregan y congregan cosas, instituciones y hombres (p. 40). A fin de conseguir una mayor profundización en esta importante idea, tomemos al Kant de la Crítica del Juicio y su llamada a pensar la naturaleza en su totalidad como la expresión de algo suprasensible. Ese "algo suprasensible" sería para Duque el proceso de invención de relaciones técnicas, que -en nuestras concepciones analíticas y lógicas nos vemos obligados a descomponer en hombres, instrumento, medio físico-. "Vivimos, nos movemos y existimos" en un entramado supra-histórico (Gefühge) que, a la vez, nos constituye a nosotros mismos, a nuestra forma de percibir/pensar y a todo nuestro obrar. Pues bien, ese "algo supra-histórico" es la clave de bóveda de toda esta obra de Félix Duque, en la dirección en que la vocación de la misma reside en 
dar razón de todo el acontecer histórico a partir del despliegue de este entramado -inobjetivable pero que, a la vez, da que pensar- en el cual residiría el único sentido de la naturaleza y de la historia.

Conseguido esto, el profesor Duque propone una serie de estadios tecno-naturales a partir de los cuales comprender y dividir la historia: la naturaleza primordial, la naturaleza orgánica, la naturaleza artesanal y la naturaleza cibernética.

1) Naturaleza Primordial: como se ha dicho, para el filósofo madrileño no hay ninguna suerte de división entre hombre y naturaleza. Más bien, la presencia humana instaura -rotura- un chaós, en el cual la técnica es la que establece al mismo tiempo la cortadura entre hombre y naturaleza sin que sea posible establecer un origen, un punto divisorio entre ambas. Ahora bien, por lo que sí cabe preguntarse es por la diferencia que hace que lo que antes era un fundamento material inerte devenga en medio de la acción del hombre a él asociado. En ese sentido, no hay origen, pero sí un desequilibrio o carencia que obliga a inventar nuevas habilidades si no se quiere perecer. Este hecho produce modificaciones de las divisiones sociales y genera en ellos las divisiones naturales -de las cuales la primera fue el incesto-. No obstante, aunque estos desequilibrios son condición necesaria del cambio de relaciones de los hombres entre sí y con el medio en que viven, no son la causa directa de ello. Es necesaria la existencia de un grupo portador de invención que se desgaja del grupo dominante y, encontrando una solución técnica a tal desequilibrio, redistribuye el ciclo de desechos, medios de producción y de consumo.

2) La naturaleza orgánica: la transformación acaecida en el estadio orgánico tiene a la base la idea de orden, orden que se manifiesta en forma de palabra y de diálogo. Los mitos cosmogónicos reflejan a la perfección -según Félix Duque- la contante faena histórica de la creación simultánea del organismo y su medio; la cual implica una "domesticación" del orden cósmico en su conjunto y el establecimiento de una "civilización" cuyas cimientos naturales $-\mathrm{y}$ por ende culturales- son ensalzados al régimen de lo ideal y divino. El nomen o omen es el guardián de la palabra sagrada -raíz sumeria "-amu" de la que brotan tanto las anteriores como las germánicas Menn y men y cuyo campo semántico articula todo cuanto tenga que ver con el dominio sobre lo real-.

3) La naturaleza artesanal: en este estadio, el artesano se convierte en el nuevo kentron. Él es el nuevo intérprete de la realidad, de quien depende lo que es exterior o interior, provechoso o desecho. De la artesanía depende la organización de un nuevo tipo de orden monarquía absoluta y Estado Nación- y el desarrollo de toda una cultura basada la universalización y matematización de la realidad.

4) La naturaleza cibernética: aquí la naturaleza depende la decisión del hombre, de la variable que éste desee utilizar con respecto a sus fines. Si la universalización por medio de la matemática y de la máquina definían el estadio anterior, ahora lo relevante es que se tome al elemento como algo fijo (natural) o como un proceso de transformación susceptible de ser aplicado a uno $u$ otro objetivo. Ahora la atenencia al suelo -natal o nacional-desaparece. Las regiones históricamente transformadas según los estadios naturales se vuelven uniformes y todo se vuelve un continuo bajo la dominación central cibernética. Si bien la electricidad y el ferrocarril fortalecen el Estado Nación anteriormente surgido, en ellas radica también el ocaso del mismo. Como bien señala Duque, la industria generada en ese plexo -y que lo conforma y mantiene- conduce a la vez a la superación del mismo y al establecimiento de una suerte de nuevo orden internacional. Con sus mismas palabras: "el establecimiento del estadio cibernético, cuyo portador de invención pretendía llevar al límite el dominio y el control de la naturaleza emancipándose para empezar de la dependencia orgánica, lleva a la conversión del mundo en un conjunto de diferencias que formas estructuras flexibles, grumos de sentido temporales" (p. 251). La hermenéutica que el autor hace de las exposiciones universales a todo este respecto en el capítulo VII resulta especialmente ilustrativa.

Precisamente, a partir del capítulo VII y concretamente del VIII en adelante, el profesor de la UAM empieza a poner en diálogo todo lo anterior con la tesitura del presente y con una nueva relectura de la crítica de la técnica heideggeriana. Después de resumir de forma iluminadora su triple división epocal de la historia - dike frente a necesidad natural; disposición de la naturaleza como objetividad a medida del sujeto; y articulación automatizada de la naturaleza como técnica del mundo- nos confronta con el legado nietzscheano y con sus más oscuras consecuencias: la voluntad de voluntad, o la voluntad sin objeto. A juicio de Félix Duque, el rasgo de la época actual es que la voluntad no domina ya lo natural sino que se conoce a sí misma como técnica mundial de la naturaleza. Ya no hay resto que gobernar; la voluntad omniabarcante es también el resto mismo. Una red que llega y conecta los más recónditos lugares.

En este sentido, Duque encuentra en el legado heideggeriano una actualidad que no puede obviarse. Precisamente, porque fue el Maestro de Alemania el que advirtió de manera más alarmante y recalcitrante acerca de la coyunda entre tecnología-democracia liberal-capitalismo de libre mercado. A raíz de esto, Félix Duque nos ofrece un estudio a la vez detallado y sintético de la crítica heideggeriana de la técnica. El cual es totalmente recomendable para cualquiera que busque adentrarse en el pensamiento de este agudo -aunque algo oscuro y demodé- autor. Partiendo de Ser y tiempo y de la aproximación positiva a la técnica que allí nos ofrece el de Messkirch, pasa luego el filósofo madrileño a abordar la crítica desconfiada de los años sombríos del Reich, para luego centrarse en las concepciones más receptivas que se manifiestan en las Conferencias de Bremen, Sendas Perdidas y Serenidad. Termina el recorrido de Duque en las de nuevo pesimistas consideraciones de finales de los años 60 y 70. Posteriormente, el catedrático se ocupa de la recepción de Heidegger por parte de la filosofía de la tecnología -norteamericana principalmente- ofreciendo una completa panorámica de aquellos autores que han recibido el legado heideggeriano de una forma crítica y constructiva: como por ejemplo Borgman, Feenberg o el francés Stiegler. 
Ya terminando, aborda el profesor emérito de la UAM (cap. IX) la metamorfosis sufrida por la técnica de la naturaleza como Ontotecnología y sus implicaciones en la actual Internet de las Cosas. Se aborda también el asentamiento urbano de esa ontotecnología en la ciudad - concretamente en lo que Duque denomina Mépolis, la no-ciudad que engloba y asume a todas las ciudades, su historia y su evolución-. Posteriormente, se trata la interacción de esa Mépolis con la Tercera y Cuarta Revolución Industrial y con los fenómenos subyacentes a ellas: la Globalización, la Migración a escala planetaria y el denominado Terrorismo Internacional. Precisamente de ahí arranca la reflexión final con que Félix Duque cierra su obra: esto es la valoración de todos estos "males actuales" y de su posible carácter preconizador de un orden nuevo o, al menos, de un cierto cambio de época.
Con todo, las coordenadas de pensamiento filosóficonatural que el pensador nos ofrece en este libro nos conducen a plantear el presente y sus circunstancias en la perspectiva no tanto de una Historia universal única sino de un conjunto de eventos - tecno-naturales- a partir de cuya coincidencia pueden darse nuevas reorganizaciones y posibilidades inéditas de futuro. ¿Podemos pensar desde ahí una nueva época? La respuesta ha de quedar abierta; pero sin lugar a dudas el aporte de Félix Duque en este libro puede brindar herramientas conceptuales sólidas para pensar y repensar actualidad e historia y -en conjunto con las demás disciplinas- abrir nuevos horizontes de sentido y significatividad -“epistemes" à la Foucault como él mismo dice- para el presente.

José Manuel Iglesias Granda 